\title{
Balok Beton Bertulang yang Diperkuat dengan Carbon Fiber Reinforced Polymer Wrap saat Dibebani Beban Gravitasi
}

\author{
Brian Widyan Hadi ${ }^{\mathrm{a}}$, Henricus Priyosulistyo ${ }^{\mathrm{b} *}$, M. Fauzie Siswanto ${ }^{\mathrm{b}}$ \\ ${ }^{\text {a }}$ Program Pascasarjana, Departemen Teknik Sipil dan Lingkungan, Universitas Gadjah Mada, Yogyakarta, 565223, Indonesia \\ ${ }^{\mathrm{b}}$ Departemen Teknik Sipil dan Lingkungan, Universitas Gadjah Mada, Yogyakarta, 565223, Indonesia
}

Keywords:

Reinforced Beam

Carbon Fiber Reinforced Polymer

SNI 2847

ACI $440.2 R$

\begin{abstract}
Innovation is developed continuously to find an optimal method of strengthening structural components. There are many strengthening methods for reinforced concrete structures. Carbon Fiber Reinforced Polymer Wrap as a flexural strengthening material according to ACI 440.2R was chosen. The research includes gravity load (dead load and live load) as the initial load during test according to SNI 2847-2013 chapter 20. This research examines the strength of the intact beam, strengthened reinforced beam, and failure pattern, respectively, compared to the intact beam's result theoretically and experimentally. The failure test results show that the maximum loads of the experiment beam were similar to the theoretical analysis with a ratio of 0.98 to 1.33. The failure patterns are shear, flexure-shear, spalling and diagonal cracks, and debonding failures. CFRPW can increase the strength and stiffness of the beams. The increase of CFRP beams (BF A and BF B) is 35,27\% and 46,24\%, respectively. The increase of stiffness ratio of $B F A$ and $B F B$ is 3,48 and 6,62 compared to BK 1 .
\end{abstract}

\begin{abstract}
ABSTRAK
Sebuah inovasi yang terus dikembangkan agar menemukan sebuah metode yang optimal dalam perkuatan komponen struktur balok. Perkuatan balok beton bertulang dapat dilakukan dalam beberapa metode. Carbon Fiber Reinforced Polymer Wrap dipilih sebagai bahan penguat lentur sesuai ACI 440.2R. Penelitian ini meliputi beban gravitasi (beban mati dan beban hidup) sebagai beban awal pada saat pengujian sesuai SNI 2847-2013 pasal 20. Penelitian ini mengkaji kekuatan balok murni, kekuatan balok yang telah diperkuat, pola keruntuhan dan perbandingan antara hasil teoritis dan eksperimental. Hasil pengujian ultimit menunjukkan bahwa balok uji serupa dengan analisis teoritis dengan perbandingan beban maksimum 0,98 dan 1,33. Pola kegagalan adalah retak geser, geser lentur, keretakan spalling dan diagonal serta kegagalan debounding. CFRPW dapat meningkatkan kekuatan dan kekakuan balok. Peningkatan kekuatan BF A 35,27\% dan BF B 46,24\% terhadap BK 1 . Peningkatan rasio kekakuan balok BF A dan BF B bila dibandingkan dengan BK 1 adalah 3,48 dan 6,62
\end{abstract}

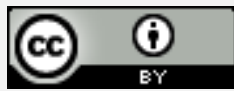

This is an open access article under the CC-BY license.

\section{Pendahuluan}

Perkuatan balok beton bertulang dapat dilakukan dalam beberapa metode. Carbon Fiber Reinforced Polymer (CFRP) Wrap dipilih sebagai perkuatan komponen struktural gedung pada permukaan balok beton bertulang. Perkuatan ini guna memberikan sebuah solusi beberapa permasalahan di lapangan antara lain adanya retak pada balok akibat pengalihfungsian ruangan dan adanya bencana gempa. Perkuatan ini meningkatkan kekuatan lentur atau tarik yang besar untuk melapisi balok yang telah terdeformasi dan retak agar memberikan kekuatan yang sesuai dengan fungsi ruangan setelah diperkuat. Penelitian ini dilakukan secara eksperimen untuk mengetahui perilaku balok yang telah terdeformasi akibat beban gravitasi (beban mati dan beban hidup). Pada eksperimen yang dilakukan, setelah diberikan perkuatan balok dapat memberikan kekuatan layan yang sama atau bahkan melebihi dari balok yang tanpa perkuatan. Penelitian ini bertujuan untuk membandingkan kekuatan balok yang diuji tanpa beban gravitasi dengan balok yang diuji dengan beban gravitasi. Mengetahui perilaku balok 
yang diperbaiki menggunakan CFRP Wrap dengan pemberian beban gravitasi, tambahan dan diuji kelayakan dengan balok yang diperkuat tanpa dibebani dan diuji kelayakan. Mengetahui perbedaan perilaku balok pada jumlah lapis pada perkuatan $C F R P W$. Membandingkan hasil penelitian dengan balok yang diperkuat tanpa diberi beban gravitasi dan diuji kelayakan [1] pada penelitian sebelumnya.

\subsection{Perkuatan Balok}

Dilaporkan oleh [2], penerapan perbaikan struktur pada bangunan yang telah mengalami kegagalan adalah upaya untuk mengembalikan fungsi struktur seperti keadaan awal setelah terjadi penurunan kekuatan. Agar bangunan yang telah rusak dapat difungsikan, perlu adanya tindakan rehabilitasi yang dapat berupa perbaikan (retrofit) atau perkuatan (strengthening). Perbaikan struktur ada beberapa jenis yaitu perkuatan menggunakan baja profil, perkuatan menggunakan Carbon Fiber Reinforce Polymer, perkuatan menggunakan metode Near Surface Mounted, perkuatan mengggunakan metode Jaketing.

\subsection{Perkuatan dengan $C F R P$}

Penelitian yang dilakukan [3] terhadap balok beton bertulang dengan CFRP Wrap telah menghasilkan Skema Wrap memberikan kinerja terbaik dalam hal meningkatkan kekuatan geser dan daktiltas balok $R C$, dibandingkan dengan balok yang dibalut dengan bentuk U yang memiliki ketebalan yang sama. Mode kegagalan balok yang dibungkus sepenuhnya adalah pecahnya FRP, lebih baik dibandingkan dengan debonding secara tibatiba pada laminasi FRP balok U-Wrapped. Pada kasus di mana balok tidak dapat sepenuhnya dibungkus, skema Uwrapping adalah pilihan yang baik. U-Wrapped balok agar mencapai kekuatan yang sama dengan balok yang dibungkus secara menyeluruh, laminasi CFRP harus terangkur untuk menghindari debonding yang rapuh.

\subsection{Pola Keruntuhan Balok}

Dalam [4], jenis keruntuhan yang terjadi pada balok dibedakan menjadi tiga, diantaranya adalah: (a) Keruntuhan tekan ( brittle failure) yang ditandai oleh hancurnya beton sebelum baja tulangan leleh saat penampang balok beton tertekan; (b) Keruntuhan seimbang (balance failure) ditandai dengan hancurnya beton dan baja tulangan mengalami leleh secara bersamaan; (c) Keruntuhan tarik (ductile failure) terjadi saat baja tulangan mengalami leleh sebelum beton hancur.

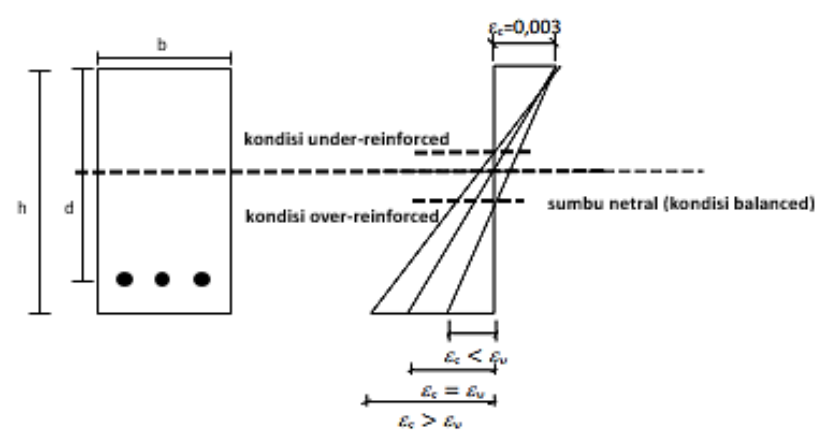

Gambar 1. Distribusi regangan ultimit pada keruntuhan lentur [4]

Pola keruntuhan pada balok dijelaskan dalam [5] yang diperkuat menggunakan CFRP dapat dibedakan menjadi tiga jenis, yaitu: debounding failure (kegagalan karena lepasnya ikatan antar material penyusun komposit), keruntuhan geser, keruntuhan pada $C F R P$ seperti pada Gambar 2, kekuatan CFRP akan berkerja secara optimal maka dikehendaki keruntuhan CFRP terlebih dahulu.

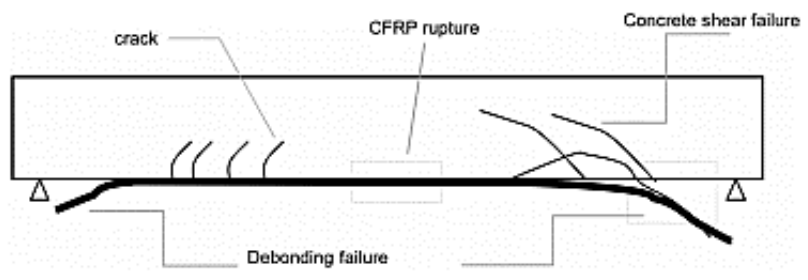

Gambar 2. Mekanisme keruntuhan balok beton bertulang dengan perkuatan CFRP [5]

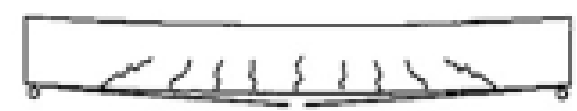

(a)

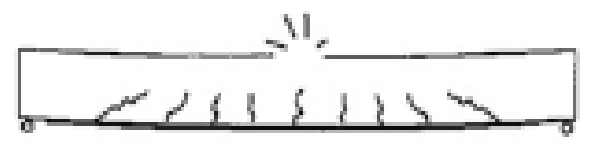

(b)

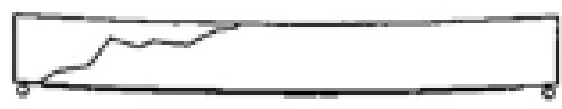

(c) 


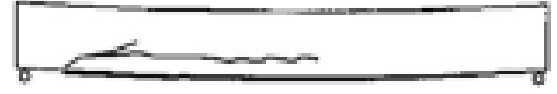

(d)

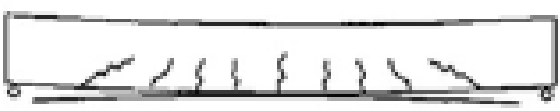

(e)

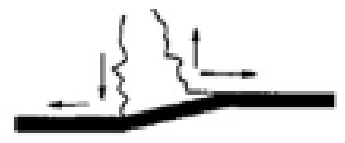

(f)

Gambar 3. Mode kegagalan balok beton bertulang diperkuat CFRP Wrap: (a) tulangan baja leleh dan pecahnya ikatan $C F R P$, (b) kegagalan lentur beton, (c) kegagalan geser, (d) debounding $C F R P$ sepanjang tulangan longitudinal, (e) lepasnya ikatan antara $C F R P$ dengan beton, (f) gagal akibat retak geser. [6]

\subsection{Pola Retak}

Jenis keretakan dibedakan menjadi lima menurut [7] diantaranya: (a) Retak lentur yang terjadi pada daerah yang mempunyai gaya geser kecil dan momen lentur lebih besar. Retak mengarah hampir tegak lurus sumbu balok; (b) Retak geser yang terjadi saat gaya geser maksimal dan tegangan aksial sangat kecil. Secara visual retak geser membentuk pola diagonal pada garis netral balok; (c) Retak geser-lentur yang terjadi setelah bagian balok mengalami retak lentur. Retak ini merupakan perambatan retak miring yang terjadi setelah retak lentur; (d) Retak punter yang terjadi saat beton menerima torsi murni dan beton akan retak dan runtuh sepanjang garis spiral $45^{\circ}$ karena tarik diagonal yang disebabkan oleh tegangan puntir; (e) Retak lekatan yang terjadi pada sekitar tulangan. Retak terjadi dikarenakan tulangan mengalami perpindahan didalam beton (interlocking).

\subsection{Teori Pemodelan Buckingham Phi}

Metode Buckingham Phi menurut [8] adalah analisis dimensi yang sering disebut teorema $\pi$ atau teorema Buckingham. Persamaan yang bermakna secara fisik yang melibatkan sejumlah $\mathrm{n}$ sebagai variabel fisik (mempunyai gaya, panjang, waktu). Langkah Analisis Metode Buckinghan $\pi$ : (a) mengidentifikasi semua variabel yang terlibat pada sistem yang dikaji; (b) menyatakan dalam sebuah notasi variabel; (c) menyatakan variabel berdimensi dasar yaitu, gaya, panjang, waktu; (d) memilih variabel yang berulang dan tak berulang, setiap eksponen variable menghasilkan kombinasi tak berdimensi; (e) menulis persamaan umum dalam variabel $\pi$ dan menentukan jumlah $\pi$. $\left(\pi_{1}, \pi_{2}, . . ., \pi_{\mathrm{n}}\right)$; (f) menyatakan bentuk akhir sebagai hubungan antara $\pi$ dan variabel yang dikaji; dan (g) tentukan kesimpulan perbandingan antara prototip dan model.

\subsection{Tegangan Lentur Balok}

Kapasitas momen nominal pada balok berdasarkan [9] dapat dihitung dengan Persamaan sebagai berikut.

$$
\mathrm{M}_{\mathrm{n}}=0,85 \cdot \mathrm{f}^{\prime} \mathrm{c} \cdot \mathrm{b} \cdot \mathrm{a}(\mathrm{d}-0,5 \mathrm{a})
$$

dimana $M_{n}$ adalah momen nominal, f'c adalah mutu beton, $\mathrm{b}$ adalah lebar balok, $\mathrm{d}$ adalah jarak dari serat tekan ke pusat tulangan longitudinal tarik dan a adalah tinggi blok tegangan balok.

\subsection{Perkuatan dengan CFRP}

ACI 440.2R-2008 [10] menyajikan cara menghitung kekuatan CFRP dalam mendukung momen layan balok.

$$
\phi M_{n}=\phi\left(M_{n s}+\psi_{f} M_{n f}\right)
$$

dimana $\Phi \mathrm{M}_{\mathrm{n}}$ adalah momen nominal terfaktor, $\mathrm{M}_{\mathrm{ns}}$ adalah kekuatan kontribusi baja tulangan dan $\mathbf{M}_{\mathrm{nf}}$ adalah kekuatan kontribusi $C F R P$.

\subsection{Kekakuan Balok}

Menurut [11] kekakuan didefinisikan sebagai gaya yang dibutuhkan untuk menghasilkan suatu besaran deformasi.

$$
\mathrm{K}=\frac{\mathrm{P}}{\mathrm{X}}
$$

dimana $\mathrm{k}$ adalah kekakuan, $\mathrm{P}$ adalah gaya yang terjadi dan $\mathrm{x}$ adalah deformasi searah beban.

\subsection{Kriteria Penerimaan Lendutan}

Lendutan yang diukur harus memenuhi persyaratan SNI 2847-2013 pasal 20. Lendutan maksimum memakai Persamaan (4) dan lendutan sisa permanen memakai Persamaan (5).

$$
\begin{aligned}
& \Delta_{1} \leq \frac{1_{\mathrm{t}}{ }^{2}}{20000 \mathrm{~h}} \\
& \Delta_{\mathrm{r}} \leq \frac{\Delta_{1}}{4}
\end{aligned}
$$

dimana $\Delta_{1}$ adalah lendutan maksimum ketika uji beban setelah ditahan $24 \mathrm{jam}, 1_{\mathrm{t}}$ adalah bentang balok terpendek, $\Delta_{\mathrm{r}}$ adalah lendutan sisa permanen dan $\mathrm{h}$ adalah tinggi balok. 


\section{Metode}

\subsection{Bahan Penelitian}

Bahan bahan yang dipakai dalam penelitian ini dapat diuraikan sebagai berikut: (a) Beton yang digunakan adalah mutu $26 \mathrm{MPa}$ dan slump $10 \pm 2 \mathrm{~cm}$. Pemilihan sesuai dengan peraturan SNI 2834-2000 dan SNI 2847 2013; (b) Baja tulangan yang dipakai produk dari PT. Inter World Steel Mills dengan D10 untuk tulangan tarik dan $\emptyset 3$ untuk sengkang dengan mutu baja $\left(f_{\mathrm{y}}\right) 420 \mathrm{MPa}$; (c) Carbon Fiber Reinforced Polymer Wrap dan Epoxy Adhesives CFRP Wrap dan Epoxy Adhesive yang dipakai dalam penelitian ini produk dari PT. Mapei Indonesia Construction Solution dengan PT. Hadira Megantara sebagai distributor yang memiliki spesifikasi fu 4800 $\mathrm{MPa}, \varepsilon$ 0,0018, $\mathrm{E}_{\mathrm{f}} 230000 \mathrm{MPa}$ dengan tebal $0.16 \mathrm{~mm}$.

\subsection{Peralatan Pengujian}

Alat yang dipakai dalam pengujian ini adalah Loading Frame, Hydraulic Jack, Mesin Uji Tekan Beton, Slump Test (kerucut Abram's), Load Cell, Strain Indicator, Strain Gauge Baja dan Beton, LVDT (Linear Variable Differential Transformer).

\subsection{Benda Uji}

Benda uji balok terdiri dari 4 buah untuk pengujian lentur. Pelaksanaan pengujian di laboratorium menggunakan ketentuan dari ASTM A370-03a [12] dan A706 [13].

\subsection{Prototip benda uji}

Penelitian ini merujuk pada kondisi bangunan prototip $21 \mathrm{~m} \times 21 \mathrm{~m}$ yang menggunakan balok portal bentang 7 meter dengan lebar balok $300 \mathrm{~mm}$ dan tinggi balok 550 $\mathrm{mm}$.

\subsection{Model benda uji}

Proses pemodelan pada penelitian ini menggunakan teori Buckingham phi theory. Secara umum teori ini menggunakan persamaan pada satuannya. Skala model terhadap prototip yang dirancang mengacu kepada: (a) Skala Gemetri $\mathrm{S}_{\mathrm{L}}=2: 1$; (b) skala bahan $\mathrm{S}_{\mathrm{E}}=$ 1:1. Dari persyaratan complete similirity didapat:

$$
\begin{aligned}
& \mathrm{L}_{\mathrm{m}}=\frac{1_{\mathrm{m}}}{\mathrm{l}_{\mathrm{p}}} \mathrm{L}_{\mathrm{p}} \rightarrow \mathrm{L}_{\mathrm{m}}=\frac{1}{\mathrm{~S}_{1}} \mathrm{~L}_{\mathrm{p}} \rightarrow \mathrm{L}_{\mathrm{m}}=\frac{1}{2} \mathrm{~L}_{\mathrm{p}} \\
& \mathrm{As}_{\mathrm{m}}=\frac{1_{\mathrm{m}}^{2}}{\mathrm{l}_{\mathrm{p}}^{2}} \mathrm{As}_{\mathrm{p}} \rightarrow \mathrm{As}_{\mathrm{m}}=\frac{1}{\mathrm{~S}_{\mathrm{l}}{ }^{2}} \mathrm{As}_{\mathrm{p}} \rightarrow \mathrm{As}_{\mathrm{m}}=\frac{1}{4} \mathrm{As}_{\mathrm{p}}
\end{aligned}
$$

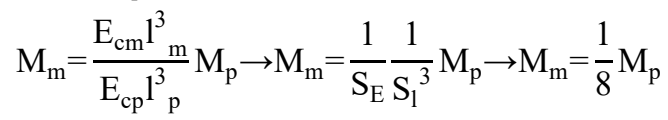

$$
\begin{aligned}
& \mathrm{P}_{\mathrm{m}}=\frac{\mathrm{E}_{\mathrm{cm}} 1^{2}{ }_{\mathrm{m}}}{\mathrm{E}_{\mathrm{cp}} 1_{\mathrm{p}}^{2}} \mathrm{P}_{\mathrm{p}} \rightarrow \mathrm{P}_{\mathrm{m}}=\frac{1}{\mathrm{~S}_{\mathrm{E}}} \frac{1}{\mathrm{~S}_{\mathrm{l}}{ }^{2}} \mathrm{P}_{\mathrm{p}} \rightarrow \mathrm{P}_{\mathrm{m}}=\frac{1}{4} \mathrm{P}_{\mathrm{p}}
\end{aligned}
$$

Mengambil bagian tengah dari prototip setelah di skala 1:2 menjadikan balok model memiliki panjang diantara titik balik momen sebesar 2 meter, lebar $150 \mathrm{~mm}$ dan tinggi $275 \mathrm{~mm}$.

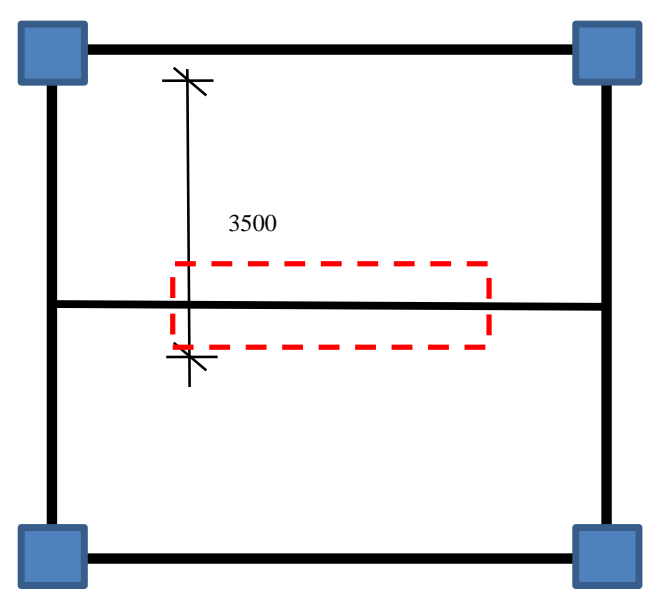




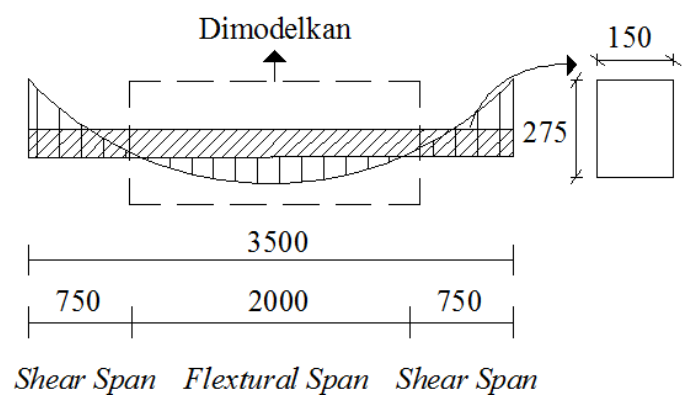

Gambar 4. Denah gedung dan balok model (skala 1:2)

\subsection{Macam-macam Benda Uji}

Berikut ini adalah benda uji yang telah dipersiapkan dalam penelitian ini diantaranya adalah: (a) Silinder beton diameter $150 \mathrm{~mm}$ dan tinggi $300 \mathrm{~mm}$; (b) Balok model diuji lentur setelah diberikan beban gravitasi di 5 titik. Visualisasi pemasangan CFRPW pada benda uji seperti Gambar 5.

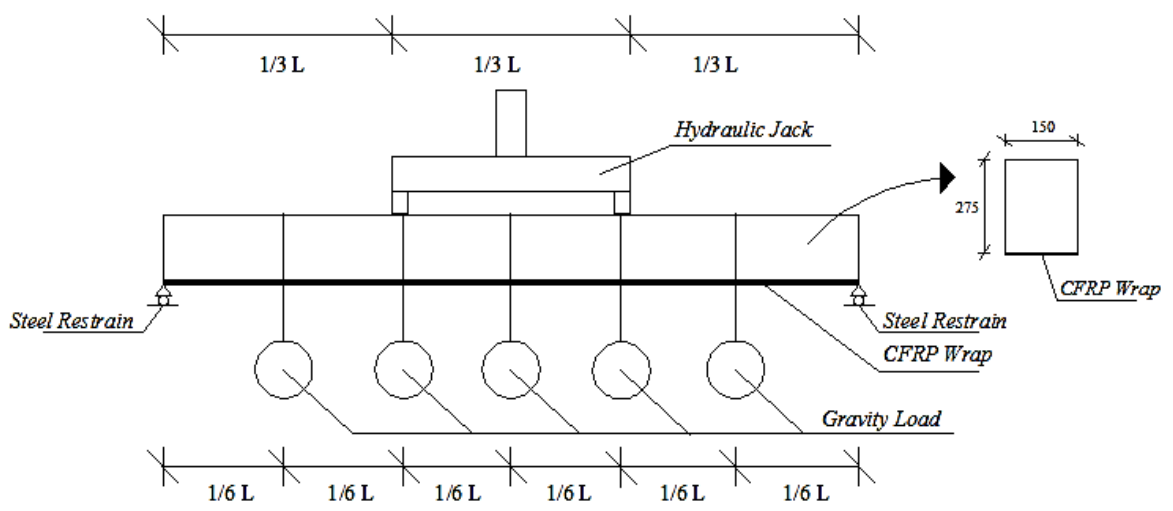

Gambar 5. Balok dibebani oleh beban gravitasi dan dilapisi $C F R P W$

\subsection{Tahapan Penelitian}

Penelitian perilaku balok yang telah diperkuat oleh CFRP dilakukan dalam beberapa tahapan sebagai berikut: (a) studi literatur; (b) Perencanaan benda uji dan pemodelan; (c) persiapan alat dan bahan uji; (d) Pembuatan benda uji untuk balok diantaranya adalah setting untuk bekisting, perakitan tulangan, pembetonan dan curing.

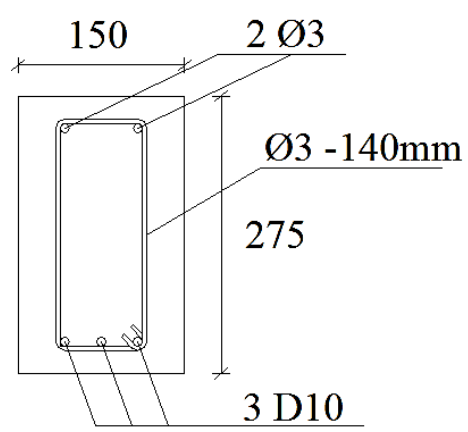

Gambar 6. Detail tulangan balok model

\subsection{Pengujian Spesimen}

Pengujian specimen meliputi (a) Pengujian tekan silinder beton dan tarik baja tulangan; (b) Pengujian lentur balok model BK-1 yang mana Balok ditekan dengan hydraulic jack pada 2 titik tekan hingga runtuh; (c) Pengujian lentur balok model BK-2 yang meliputi pemebanan gravitasi dipasang (dihitung berdasarkan beban mati yang bekerja 
pada balok), Balok diuji kelayakannya sesuai [1] pasal 20 dan Selanjutnya balok ditekan dengan hydraulic jack pada 2 titik hingga runtuh. Pengujian lentur balok model dengan $C F R P W 1$ lapis (BF-A) melalui tahapan sebagai berikut: (a) Balok dibebani oleh berat sendiri (gravitasi) seperti pada Gambar 6 atau Gambar 7; (b) Balok dibebani dengan hydraulic jack $(0,15 D L+1,5 L L)$ dalam 4 tahap. Pembebanan dibiarkan selama 24 jam dan diukur lendutannya secara berkala (SNI 2847-2013 Pasal 20); (c) Selanjutnya beban hydraulic jack dilepas dan oleh beban gravitasi diukur lendutan sisanya; (d) Balok dilapisi CFRP Wrap 1 lapis; (e) Selanjutnya balok diberikan beban hydraulic jack seperti butir b dan c; (f) Pengujian lentur balok model dengan CFRPW 3 lapis (BF-B) dengan mekanisme Balok diuji tekan hingga runtuh sesuai dengan ACI 440.2R-2008.

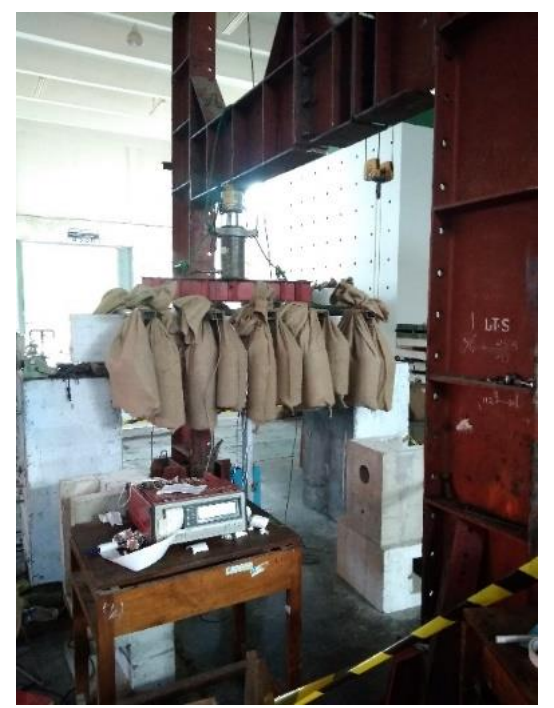

Gambar 7. Beban awal pada pengujian balok

Tabel 1. Kode Balok dan Keterangan

\begin{tabular}{ll}
\hline \multicolumn{1}{c}{ Kode } & \multicolumn{1}{c}{ Keterangan } \\
\hline BK-1 & Balok kontrol yang tidak dibebani gravitasi, tidak diuji kelayakan tetapi diuji ultimit \\
BK-2 & Balok dibebani gravitasi sebesar 10,75 kN, diuji kelayakan [1] (pasal 20) tahap 1 sebesar 11,75 kN \\
& dan diuji ultimit \\
BF-A & Balok dibebani gravitasi, diuji kelayakan tahap 1, diperkuat CFRPW 1 lapis, balok diberi beban \\
& hydraulic jack sebesar 10 kN, diuji kelayakan [1] (pasal 20) tahap 2 sebesar 13,25 kN dan uji \\
& ultimit \\
BF-B & Balok dibebani gravitasi, diuji kelayakan tahap 1 dan diperkuat CFRPW3 lapis, balok diberi beban \\
& hydraulic jack, diuji kelayakan [1] (pasal 20) tahap 2 dan uji ultimit \\
\hline
\end{tabular}

\section{Hasil}

\subsection{Hasil Uji Eksperimental}

Penelitian ini dilakukan secara eksperimental yang dilakukan di Laboratorium Struktur Universitas Gadjah Mada. Hasil yang didapat adalah sebagai berikut.

\subsubsection{BK-1}

Gambar 8 melaporkan hubungan gaya-lendutan BK-1 saat diberi beban uji kelayakan sebesar $11,75 \mathrm{kN}$ (25,27\% dari beban ultimit) dan mengalami lendutan sebesar 3,66 $\mathrm{mm}$. Saat diuji hingga runtuh, balok mengalami lendutan sebesar 33,26 mm dengan gaya ultimit sebesar 46,5 $\mathrm{kN}$. Balok BK-1 rusak oleh lentur, dan pada beban sebesar $31,65 \mathrm{kN}$ muncul retak geser. Pada saat beban terus ditingkatkan, retak lentur dan geser lebih nyata. Pola retak balok tersebut menandakan bahwa daerah lentur dan geser bekerja bersama. Pola kegagalan balok adalah retak lentur-geser.

\subsubsection{BK-2}

Gambar 9 memperlihatkan BK-2 yang diuji kelayakan tahap 1 (29,41\% dari beban ultimit) mengalami lendutan sebesar 1,45 mm > 0,73 mm (batasan maksimum sesuai Persamaan (4)). 


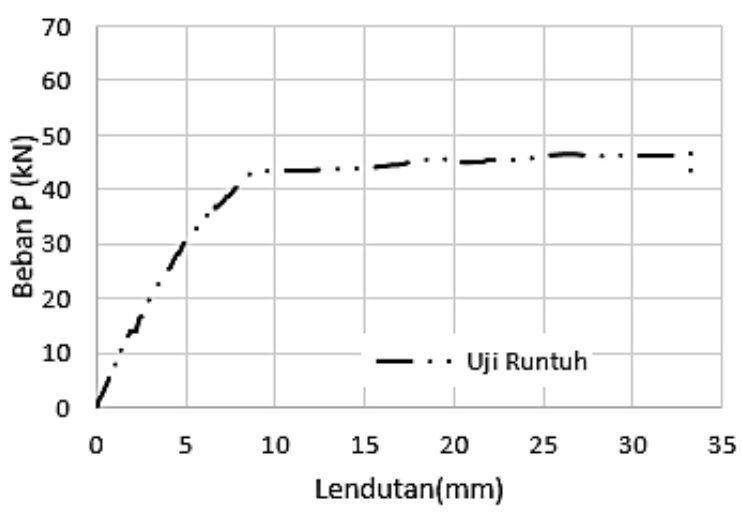

Gambar 8. Diagram P- $\Delta$ BK-1

Ketika beban uji kelayakan dilepas, lendutan yang tersisa $\left(\Delta_{\mathrm{r}}\right)$ sebesar $0,93 \mathrm{~mm}>0,36 \mathrm{~mm}$ (batasan maksimum sesuai Persamaan (5). Lendutan balok BK-2 saat diuji kelayakan tidak memenuhi syarat.

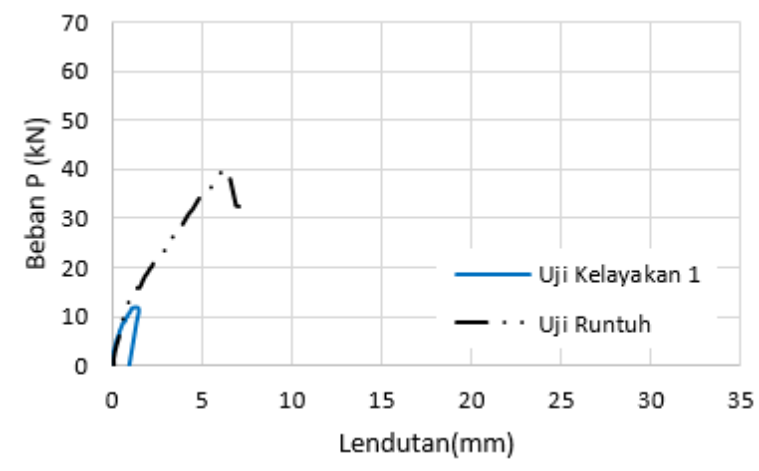

Gambar 9. Diagram P- $\Delta$ BK-2

Proses uji dilanjutkan hingga mencapai beban ultimit. Hasil yang didapatkan, balok mengalami lendutan sebesar 6,39 mm dengan gaya ultimit sebesar 39,95 kN. Pada BK2 , retak geser timbul saat beban mencapai $31,95 \mathrm{kN}$. Ketika beban terus ditambah, retak geser lebih cepat melebar dibandingkan retak lentur. Kerusakan balok didominasi pada kegagalan geser.

Gambar 8 sampai dengan Gambar 9 memperlihatkan perbedaan grafik pada BK-1 dan BK-2. Hasil dapat juga dilihat pada Gambar 13. Hasil BK-2 terhadap BK-1 yang memperlihatkan hasil kekuatan balok turun 16,4\%. Hal tersebut disebabkan adanya beban gravitasi dan uji kelayakan tahap 1 pada BK-2. Pola kegagalan balok adalah pola retak lentur-geser

\subsubsection{BF-A}

Gambar 10 menunjukkan hasil diagram gaya-lendutan BF-A. Proses uji kelayakan tahap 1 (18,68\% dari beban ultimit) menghasilkan lendutan $\left(\Delta_{1}\right)$ sebesar $1,13 \mathrm{~mm}>$ $0,73 \mathrm{~mm}$ (batasan maksimum pada Persamaan (4). Ketika beban uji kelayakan dilepas, lendutan yang tersisa $\left(\Delta_{\mathrm{r}}\right)$ sebesar 0,73 $\mathrm{mm}>0,28$ (batasan maksimum sesuai Persamaan (5). Lendutan balok BF-A saat diuji kelayakan tidak memenuhi syarat.

Setelah diperkuat CFRP Wrap 1 lapis, balok BF-A diberi beban hydraulic jack $(15,89 \%$ dari beban ultimit). Uji kelayakan tahap 2 (21,06\% dari beban ultimit), BF-A mengalami lendutan $\left(\Delta_{1}\right)$ sebesar $2,15 \mathrm{~mm}>0,73 \mathrm{~mm}$ (batasan maksimum sesuai Persamaan (4). Setelah beban uji kelayakan dilepas, lendutan yang tersisa $\left(\Delta_{r}\right)$ sebesar 1,53 mm > 0,54 (batasan maksimum sesuai Persamaan (5). Lendutan balok BF-A saat diuji kelayakan tidak memenuhi syarat.

Pengujian dilanjutkan sampai ultimit tercapai. Hasil yang didapatkan menunjukkan bahwa lendutan sebesar 12,91 mm dengan gaya tekan maksimum sebesar $62,9 \mathrm{kN}$. Gaya ultimit pada BF-A mengalami kenaikan kekuatan terhadap BK-1 sebesar 35,27 \%. Bila dibandingkan terhadap BK 2, gaya ultimit meningkat sebesar 57,45 \%. Pola retak dan kegagalan balok adalah geser dengan concrete cover separation failure (kegagalan karena lepasnya ikatan selimut beton dengan lapisan polimer dengan CFRP Wrap).

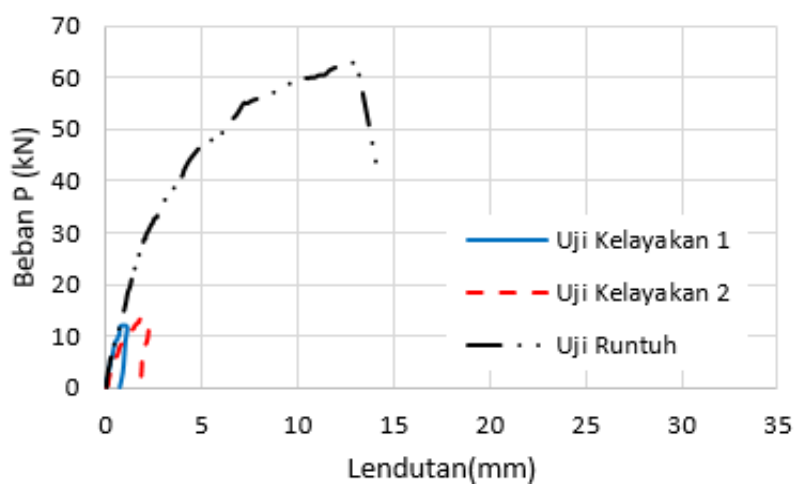

Gambar 10. Diagram P- $\Delta$ BF-A

\subsubsection{BF-B}

Gambar 11 menunjukkan hasil diagram gaya-lendutan BF-B. Balok diuji kelayakan tahap 1 (17,28\% dari beban ultimit) dan mengalami lendutan sebesar 1,14 mm >0,73 mm (batasan maksimum sesuai Persamaan (4). Ketika beban uji kelayakan dilepas, balok menyisakan lendutan $\left(\Delta_{\mathrm{r}}\right)$ sebesar 0,68 $\mathrm{mm}>0,29$ (batasan maksimum sesuai Persamaan (5). Lendutan balok BF-B saat diuji kelayakan tidak memenuhi syarat.

Setelah diperkuat CFRPW 3 lapis, balok diberikan beban tambah dengan hydraulic jack (14,71\% dari beban ultimit) 
dan diuji kelayakan tahap 2 (19,49\% dari beban ultimit). Pengujian ini mengakibatkan balok mengalami lendutan $\left(\Delta_{1}\right)$ sebesar 1,84 $\mathrm{mm}>0,73 \mathrm{~mm}$ (batasan maksimum sesuai Persamaan (4). Beban BF-B dilepas dan menyisakan lendutan $\left(\Delta_{\mathrm{r}}\right)$ sebesar $1,33 \mathrm{~mm}>0,46 \mathrm{~mm}$ (batasan maksimum sesuai Persamaan (5). Lendutan balok BF-B saat diuji kelayakan masih belum memenuhi syarat.

Pengujian dilanjutkan dengan uji ultimit. BF-B mengalami lendutan sebesar 7,35 mm dengan gaya tekan maksimum sebesar 68,0 kN. Pola retak dan kegagalan balok adalah geser dengan critical diagonal crack debounding failure (kegagalan katastropik dengan retak diagonal kritis disebabkan oleh perpindahan gaya geser pada balok)

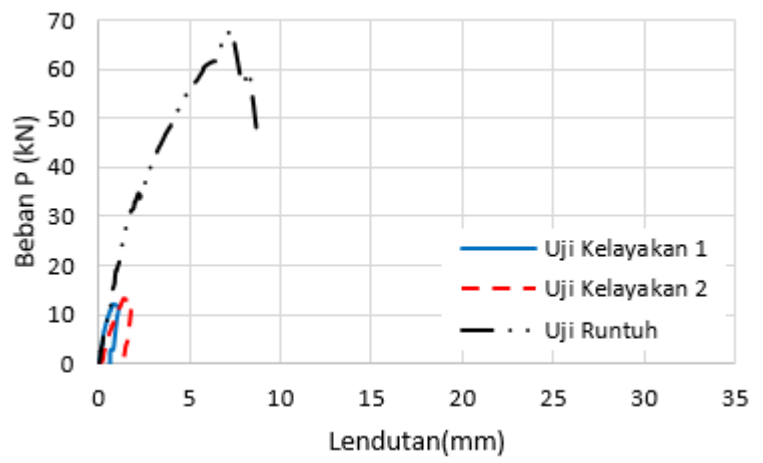

Gambar 11. Diagram P- $\Delta$ BF-B

Perbandingan hasil diagram gaya-lendutan antara BF-B dan BF-A dapat dilihat pada Gambar 10, Gambar 11 dan Gambar 13. Hasil BF-B telihat lebih tinggi kekuatannya tetapi lebih kecil lendutan maksimalnya bila dibandingkan dengan BF-A. Nilai kekuatan antara BF-B dan BF-A berbeda sebesar $8,11 \%$. Hal tersebut disebabkan oleh perkuatan $C F R P W 3$ lapis pada BF-B membuat balok semakin kaku dibanding BF-A yang diperkuat $C F R P W 1$ lapis. Gaya ultimit pada BF-B mengalami kenaikan kekuatan terhadap BK-1 sebesar 46,24 \%. Bila dibandingkan terhadap BK-2, gaya ultimit meningkat sebesar $70,21 \%$.

\subsubsection{Perbandingan Hasil Uji Kelayakan}

Hasil uji kelayakan pada Gambar 12 menunjukkan bahwa antara BF-A, BF-B dan BK-2. Lendutan terbesar terlihat pada BF-A diikuti BF-B dan BK-2. Hasil BF-A dan BF-B lendutan lebih besar daripada BK-2 dimungkinkan akibat adanya beban yang ditambahkan melalui hydraulic jack. Pada uji kelayakan tahap 2 mengakibatkan timbulnya retak pada balok.

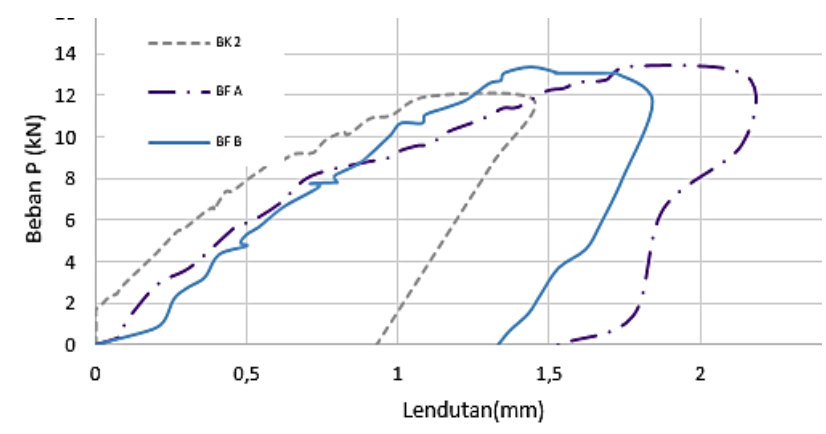

Gambar 12. Grafik gaya-lendutan uji kelayakan

\section{Pembahasan}

\subsection{Perbandingan Hasil Uji Ultimit}

Setelah melewati pengujian kelayakan tahap 1 dan tahap 2, beban di kosongkan serta hanya meninggalkan beban gravitasi, balok BK-2, BF-A, BF-B diuji hingga runtuh. Hasil uji balok hingga runtuh BK-1, BK-2, BF-A, BF-B dapat dilihat pada Gambar 15. Hasil uji yang dilakukan memiliki perbedaan dengan penelitian yang telah dilakukan oleh [14].

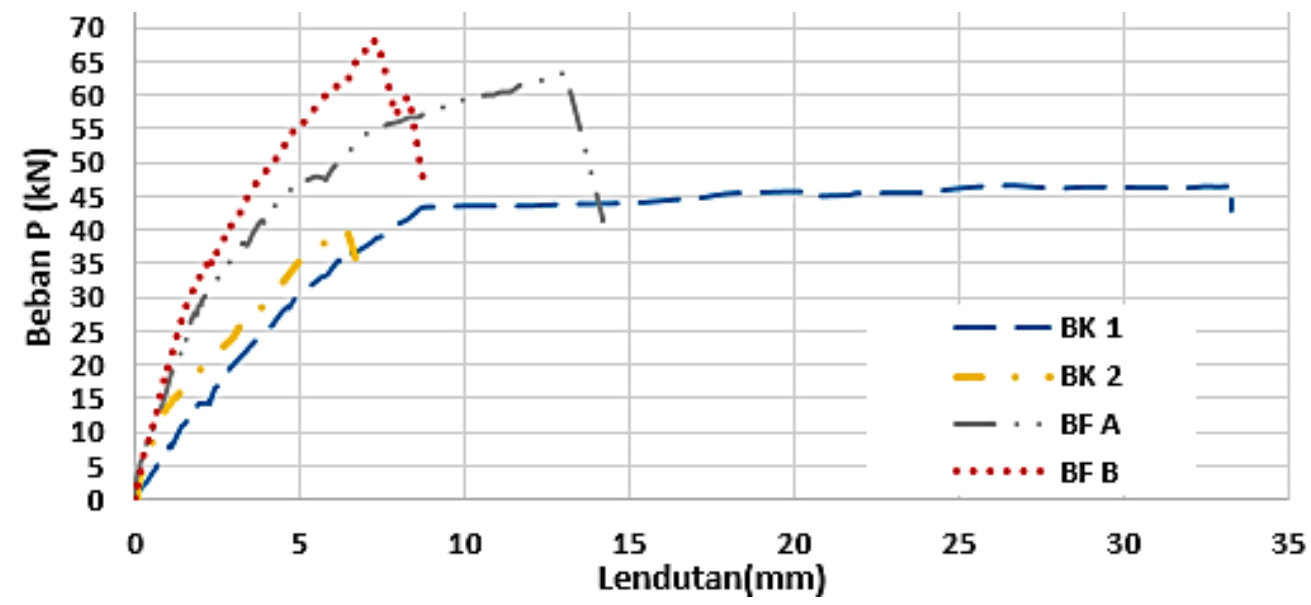

Gambar 13. Grafik tegangan-lendutan saat uji hingga runtuh 
Berdasarkan hasil analisis pada Gambar 13 dapat disimpulkan bahwa, perkuatan CFRP Wrap efektif untuk memperbesar kekuatan layan pada sebuah balok. Terbukti pada BK 1 yang kekuatannya sebesar 46,5 kN lebih kecil dibandingkan BF-A yang diperkuat CFRP Wrap 1 lapis nilai gaya maksimum $62,9 \mathrm{kN}$ dan BF-B yang diperkuat CFRP Wrap 3 lapis nilai gaya maksimum $68 \mathrm{kN}$. Peningkatan balok yang diperkuat $C F R P W 1$ lapis sebesar $35,27 \%$ dan balok dengan 3 lapis sebesar 46,24\%.

Sementara dalam penelitian Petrico dkk [14], penelitian dilakukan dengan mutu beton $20 \mathrm{MPa}$, dimensi 100 x 150 x $1200 \mathrm{~mm}$, tulangan tarik $3 \varnothing 10$, tulangan tekan $2 \varnothing 6$, begel $\varnothing 6-100$, tebal CFRPW $1 \mathrm{~mm}$ dan kuat tarik 834 MPa. Balok kontrol rata-rata dapat menahan $49,14 \mathrm{kN}$ dan balok yang diberi perkuatan dapat menahan rata-rata 72,54 kN. Perkuatan menyebabkan kekuatan balok meningkat 47,62\%. Perbedaan hasil dimungkinkan adanya perbedaan dimensi balok dan material yang dipakai. Perbedaan juga dimungkinkan disebabkan pada alur sistem pembebanan. Sistem pembebanan awal sebesar $75 \%$ dari rata-rata beban maksimum balok kontrol mengacu kepada [14].

\subsection{Kekakuan Balok}

Kekakuan dihitung dengan mempertimbangkan kemiringan pada kenaikan kurva beban dengan perpindahan dari semua balok. Hal ini dapat dilihat pada Tabel 2 yang dihitung dengan menggunakan Persamaan (3). BK-2 memiliki rasio kekakuan sebesar 3,47 terhadap BK-1. BF-A meningkatkan kekakuan 2,48 terhadap BK1 dan 0,78 terhadap BK-2. BF-B meningkatkan rasio kekakuan sebesar 5,61 terhadap BK-1 dan 1,47 terhadap BK-2. Hasil ini disebabkan oleh penambahan beban gravitasi, uji kelayakan dan perkuatan $C F R P W$.

\subsection{Perbandingan Kapasitas balok antara Analisis dan Eksperimen}

Hasil eksperimen yang telah dilakukan bila dibandingkan dengan hasil analisis teori (lihat pada Tabel 3). menunjukkan bahwa hasil eksperimen mengalami peningkatan kapasitas beban maksimum terhadap analisis teori. Pada balok BK-1 meningkat sebesar 33\%, BK-2 meningkat sebesar $15 \%$ dan BF-A meningkat sebesar $12 \%$, sedangkan untuk BF-B mengalami penurunan sebesar $2 \%$.

Tabel 2. Ekivalensi Kekakuan

\begin{tabular}{cccccc}
\hline Benda Uji & $(\mathrm{a})$ & $(\mathrm{b})$ & $(\mathrm{a} / \mathrm{b})$ & $\begin{array}{c}\text { Rasio } \\
\text { (terhadap BK-1) }\end{array}$ & $\begin{array}{c}\text { Rasio } \\
\text { (terhadap BK-2) }\end{array}$ \\
& $\mathrm{Pu}(\mathrm{N})$ & $\delta \mathrm{u}(\mathrm{mm})$ & $\mathrm{K}(\mathrm{N} / \mathrm{mm})$ & - & - \\
BK-1 & 46500 & 33,26 & 1398,08 & 3,47 & - \\
BK-2 & 39950 & 6,39 & 6251,96 & 2,48 & 0,78 \\
BF-A & 62900 & 12,91 & 4872,19 & 5,61 & 1,47 \\
BF-B & 68000 & 7,35 & 9251,70 & \\
\hline
\end{tabular}

Tabel 3. Perbandingan antara analisis dengan eksperimen

\begin{tabular}{cccc}
\hline Kode & $\begin{array}{c}(\mathrm{a}) \\
\text { Eksperimen }(\mathrm{kN})\end{array}$ & $\begin{array}{c}(\mathrm{b}) \\
\text { Analisis }(\mathrm{kN})\end{array}$ & $\begin{array}{c}(\mathrm{a} / \mathrm{b}) \\
\text { Rasio }\end{array}$ \\
\hline BK-1 & 46,5 & 34,873 & 1,33 \\
BK-2 & 39,95 & 34,873 & 1,15 \\
BF-A & 62,9 & 55,955 & 1,12 \\
BF-B & 68,0 & 69,523 & 0,98 \\
\hline
\end{tabular}

\section{Simpulan}

Berdasarkan hasil pengujian dan hasil pembahasan yang telah dilakukan, dapat disimpulkan sebagai berikut: (a) Pada pengujian kelayakan tahap 1 balok tidak ada tandatanda kerusakan. Retak pada balok muncul saat uji kelayakan tahap 2; (b) Rasio kekakuan balok BF-A, BFB terhadap BK-1 adalah berturut-turut 2,48 dan 5,61; (c) Persentase pertambahan kekuatan balok dengan perkuatan CFRP 1 lapis sebesar 35,27\% terhadap balok kontrol BK-1. Pada penelitian Petrico dkk (2014) pertambahan kekuatan balok sebesar 47,62\%. (d) Persentase pertambahan kekuatan balok dengan perkuatan CFRP 1 lapis sebesar 35,27\% terhadap balok kontrol BK-1. Pada penelitian Petrico dkk (2014) pertambahan kekuatan balok sebesar 47,62\%; (e) Perbedaan hasil BK-1 dan BK-2 sebesar 16,4\% disebabkan oleh adanya beban gravitasi; (f) Perbandingan antara hasil eksperimen dan teori sesuai dengan ACI 404.2R dalam rasio sebesar 1,33 dan 1,15 untuk balok kontrol, untuk balok yang diperkuat 1 lapis CFRPW sebesar 1,12, untuk balok yang diperkuat CFRPW 3 lapis 
sebesar 0,98; (g) Seluruh balok uji dapat dikategorikan sebagai balok daktail (underreinforced).

\section{Daftar Rujukan}

[1] Badan Standardisasi Nasional, SNI 2847 Persyaratan Beton Struktural untuk Bangunan Gedung. Jakarta: Badan Standardisasi Nasional, 2013.

[2] A. Latip, "Studi perbaikan elemen kolom struktur bangunan gedung dengan sistem kolom komposit," in Prosiding Seminar Hasil Penelitian Politeknik Negeri Ujung Pandang, 2018, pp. 88-94.

[3] H. H. Mhanna, R. A. Hawileh, and J. A. Abdalla, "Shear Strengthening of Reinforced Concrete Beams Using CFRP Wraps," Procedia Struct. Integr., vol. 17, pp. 214-221, 2019, doi: 10.1016/j.prostr.2019.08.029.

[4] Y. F. F. Sofyan, "Perilaku material Retrofit Wiremesh dan SCC dengan overlapping tulangan pada sepertiga bentangan," Universitas Hasanuddin, 2018.

[5] E. K. Pangestuti, J. Prihanantio, Nuroji, and Antonius, "Flexural strength of reinforced concrete beam with CFRP," Malaysian Constr. Res. J., vol. 30, no. 1, pp. 59-72, 2020.

[6] S. M. S. Syed Mazlan, S. R. Abdullah, S. Shahidan, and S. R. Mohd Noor, "Failure behaviour of concrete prisms strengthened by various bond widths of carbon fibre reinforced polymer (CFRP)," in MATEC Web of Conferences: ISCEE, Apr. 2017, vol. 103, doi: 10.1051/matecconf/201710302015.
[7] A. Chelcea, "Studi perbandingan pola retak pada beton normal dan beton dengan sambungan model takik akibat beban siklik lateral," Universitas Hasanuddin, 2017.

[8] B. Suhendro, Teori Model Struktur dan Teknik Eksperimental. Yogyakarta: Beta Offset, 2000.

[9] H. Priyosulistyo, Struktur Beton Lanjut: Bahan Ajar Universitas Gadjah Mada. Yogyakarta: Universitas Gadjah Mada, 2010.

[10] American Concrete Institute, “ACI 440.2r Guide for the Design and Construction of Externally Bonded FRP Systems for Strengthening Concrete Structures," Farmington Hills, 2008.

[11] N. Rahmayani, "Pengaruh aspek rasio (Hw/Lw) terhadap daktilitas dan kekakuan pada dinding geser bertulangan horizontal berjarak rapat di bawah pembebanan siklik (Quasi-Statis)," Universitas Brawijaya, 2017.

[12] ASTM International, ASTM A370-03a: Standard Test Methods and Definitions for Mechanical Testing of Steel Products. 2003.

[13] ASTM International, ASTM-A706, Standard Specification for Deformed and Plain Low-Alloy Steel Bars for Concrete Reinforcement. 2016.

[14] G. I. Petrico, "Perbandingan kekuatan lentur balok beton bertulang dengan menggunakan perkuatan CFRP dan GFRP," J. Mhs. Jur. Tek. Sipil Univ. Brawijaya, vol. 1, no. 2, 2014. 